\title{
Seni Grafis Yogyakarta dalam Wacana Seni Kontemporer
}

\author{
Wiwik Sri Wulandari \\ Jurusan Seni grafis -Institut Seni Indonesia-Yogyakarta
}

\begin{abstract}
The Indonesian visual art movement are through hard time, struggling in response to the ever happen complexity of art in the world around; as experience by Yogyakarta's print making. Thus, it is interesting to know how it survive and contribute to the Indonesian visual art. The presented paper focuses on understanding the movement of Yogyakarta's printmaking in relation to the discouse of Indonesian contemporary art through visual and conceptual analysis. Results show that visual expressions of the Yogyakarta's printmaking has visually and conceptually evolved following the latest development in the contemporary art discourse.
\end{abstract}

Keywords: graphics art; contemporary art discourse.

\section{Pendahuluan}

Keberadaan kota Yogyakarta yang sedemikian kompleks dengan rajutan sejarah dan pertumbuhan kesenian sehingga melahirkan sebuah spirit kota tersendiri. Kemudian membentuk sebuah predikat sebagai salah satu barometer kesenian di Indonesia. Di kota Yogyakarta tumbuh dan berkembang tokoh-tokoh, peristiwaperistiwa, semangat, pemikiran, teknik, gaya serta nilai-nilai yang memiliki karakteristik yang dilatarbelakangi persoalan sosial, budaya, ekonomi, politik dan ideologi yang tumbuh beriringan. Salah satu bentuk karya senirupa yang lahir dari kota ini adalah seni grafis. Beberapa tokoh seni grafis yang dikenal mencetuskan dan membangun pencitraan seni grafis Yogyakarta awal adalah seniman seperti Affandi, Suromo, dan Abdul Salam.

Seni grafis modern didefinisikan secara konvensional sebagai karya dua dimensional yang memanfaatkan proses cetak seperti cetak tinggi (relief print), cetak dalam (intaglio), cetak datar (planografi), dan cetak saring (serigrafi, screen printing) yang menjadi bagian dalam konstruksi wilayah seni murni. Namun sejauh perkembangan teknologi cetak, konsepsi konvensional ini perlu dipertanyakan ulang kembali apakah nilai-nilai konvensi yang telah disepakati tersebut haruslah menjadi stagnan dan tak berkembang, sementara perkembangan jaman dengan segala dimensinya terus bergerak ke depan.

Jejak perkembangan seni grafis modern Indonesia dapat diketahui sejak kelahiran Republik Indonesia. Seni grafis Indonesia menyatakan kehadirannya 
dengan karya-karya yang secara estetik bermutu, dan secara politik lantang menggemakan suara dari "bangsa muda menjadi.....", mengutip salah satu bait syair Chairil Anwar seorang penyair terkemuka tanah air. Heroisme, patriotisme, pergulatan artistik, dan kecerdikan mengakali situasi yang menekan, menemukan mediumnya pada pahatan lino. Dari sanalah, satu sisi dari Indonesia menjelmakan diri dalam pergaulan antarbangsa. [1]

Sejarah menyebutkan bahwa seni grafis lahir dari kebutuhan-kebutuhan untuk mempropagandakan gerakan politik kemerdekaan Indonesia khususnya pada dasawarsa 1940-an sampai 1950-an. Dalam hal ini perlu mengingat eksplorasi seni yang dilakukan Affandi, Abdul Salam, Suromo, Baharuddin Marasutan dan Mochtar Apin. [2]

Para perintis dalam seni grafis adalah juga seorang pelukis atau ilustrator, dan ternyata peran profesi rangkap inilah yang mewarnai perjalanan seni grafis Indonesia. Namun yang patut dicatat pada perkembangan awal kemunculan seni grafis adalah penjelajahan medium dalam merespon zamannya. Penjelajahan ke dalam medium tersebut dapat menyingkapkan kemungkinan-kemungkinan ekspresi baru. Penjelajahan seperti itu adalah upaya berharga, yang pada akhirnya tidak cuma memperkaya dunia seni tetapi juga masyarakat luas pada umumnya. Catatan ini yang kiranya perlu dicermati dalam perkembangan seni grafis Indonesia saat ini dalam menghadapi berbagai kemungkinan medium yang semakin beragam di jaman dengan kemajuan teknologi.

Pada tahap selanjutnya mencatat bahwa peran-peran perguruan tinggi seperti FSRD -ITB, FSR-ISI Yogyakarta, FSRD-IKJ dan lain-lain, menjadi penyelenggara sekaligus fasilitator program studi seni grafis telah berhasil melahirkan sejumlah lulusan grafis yang sebagian masih bertahan dan eksis dalam percaturan dunia seni rupa lokal maupun internasional. Di antaranya adalah para dosen seni grafis dan pengajar seni rupa, mereka antara lain Eka Suprihadi, Sun Ardi, Edi Sunaryo, dan lain-lain di Yogyakarta. Sedangkan nama seperti Mochtar Apin, A.D. Pirous, T. Sutanto, Kaboel Suadi, Setiawan Sabana, dan lain-lain di Bandung.

Catatan mengenai pentingnya peran pendidikan tinggi dalam perkembangan seni rupa modern Indonesia dan dampak kesadaran kritisisme perupa juga disebutkan oleh Sanento Yuliman secara khusus dalam bukunya Dua Seni Rupa demikian:

Pendidikan tinggi mempunyai dampak penting terhadap kesadaran di kalangan perupa. Kita menyaksikan semakin banyak dan mendalam masukan informasi tentang seni rupa internasional, terutama Barat. Bersamaan dengan itu, para perupa terdidik juga peka terhadap isu dan 
diskusi di kalangan intelektual tentang masalah dunia dan negeri berkembang, misalnya masalah lingkungan - termasuk lingkungan sosial dan budaya. Pendidikan seni rupa itu juga mendorong kesadaran yang lebih tajam tentang kerja seni - tentang bahan, proses, unsur-unsur bentuk dan pengubahannya dan lain-lain - dan dari situ mendorong sikap menjelajah atau sikap eksperimental, dan sikap kritis. [3]

Hal inilah yang memicu berbagai kecenderungan baru dalam dunia seni rupa yang lekat dengan persoalan kreativitas serta selalu ingin menghadirkan sesuatu yang baru. Para perupa atau seniman selalu ingin menciptakan karya-karya baru dengan sikap menjelajah, eksperimental dan kritis dipengaruhi berbagai pemikiran maupun perkembangan teknologi baru, tidak terkecuali dengan pegrafis.

\section{$2 \quad$ Proses dan Wujud Seni Kontemporer Indonesia}

Konsepsi seni rupa kontemporer Indonesia ditumbuh kembangkan dan dipicu oleh munculnya Gerakan Seni Rupa Baru (GSRB) yang berlangsung pada tahun 1975. Embrio pemicunya berawal dari kegiatan lingkungan akademis seni rupa dengan segala konstruksi nilai yang dibangun atas nama lembaga-lembaga seni dan mengganggap sebagai yang legitimate, seakan berjalan begitu mulus tanpa suatu hambatan apa pun. Hingga suatu waktu, kegelisahan yang selama ini ternyata dipendam oleh sebagian para mahasiswa yang kritis, demikian terurai melalui peristiwa munculnya Gerakan Seni Rupa Baru atau disingkat dengan GSRB. Titik pemicu awal mula dari letupan yang lebih besar adalah momen Desember Hitam (Black December) pada tahun 1974.

Pada saat itu dilakukan pemberian penghargaan terhadap karya seni yang dianggap terbaik, diberikan kepada lima orang pelukis oleh Dewan Juri Pameran Besar Seni Lukis Indonesia (1974). Protes yang dilayangkan oleh para mahasiswa yang kritis kepada dewan juri bahwa: karya-karya tersebut dianggap bercorak ragam sama, yakni dekoratif dan lebih mengabdikan demi kepentingan "konsumtif". Karena memperoleh jalan buntu terhadap tututan yang diajukan, maka meledaklah kemudian gerakan perlawanan para seniman muda sebagai protes yang kemudian memiliki implikasi lebih luas secara sosial-politik; tidak sekedar melawan kemapanan nilai-nilai estetik-artistik, namun melebar menjadi medium untuk melancarkan kritik sosial (atas segala ketimpangan sosial yang terjadi ketika itu). [4] GSRB muncul pada tahun 1975 hingga 1979, pada masa pemerintahan Orde Baru gerakan lahir dari kandungan lingkungan akademik yang dimotori oleh para mahasiswa Akademi Seni Rupa (ASRI) Yogyakarta dan sejumlah mahasiswa dari Institut Teknologi Bandung (ITB). Konteks kelahiran gerakan ini menghantarkan dunia seni rupa Indonesia melahirkan pemahaman baru atas persoalan ideologis kesenian; konsepsi estetika pada 
dunia seni rupa; subject matter; batasan-batasan akademik, hingga menyentuh persoalan-persoalan interpretasi subjektivitas.

Selain GSRB, catatan selanjutnya dalam perjalanan proses terwujudnya sejarah seni kontemporer di Indonesia adalah pengaruh seni kontemporer dunia dalam medan seni rupa Indonesia yang mulai tumbuh pada akhir dekade 1980-an. Beberapa indikator yang menandainya antara lain adalah interaksi para seniman dan pengajar seni dengan dunia internasional (melanjutkan studi atau melalui pameran-pameran internasional, keikutsertaan seniman Indonesia dalam ajang kompetisi seni rupa internasional), munculnya institusi-institusi independen seperti Galeri Seni Cemeti dan Yayasan Seni Cemeti (1989) di Yogyakarta, tumbuh kembangnya galeri-galeri seni di beberapa kota di Indonesia. Selain itu, diikuti oleh maraknya wacana kuratorial dalam penyelenggaraan pameran, dan situasi sosial-politik yang hegemonik represif pada masa orde baru memicu tumbuh kembangnya wacana seni kontemporer dalam dunia kesenirupaan Indonesia.

Sejalan dengan perkembangan zaman beserta konsepsi yang terus berjalan dan berubah timbullah tantangan baru yang lebih kompleks. Memasuki dekade 1990-an, sejalan dengan hadirnya dunia teknologi cetak digital yang lebih handal, eksplorasi media dan teknologi beserta konsep seni posmodernisme yang dibumbui semangat pluralisme, keberagaman baik dalam penggunaan media, teknologi, 'anything goes' dalam penyajian sebuah karya seni, membawa tantangan persoalan baru. Sebuah kontradiksi yang sangat bertolak belakang dengan konsep seni grafis yang memakai kaidah konvensional.

Pendekatan seni kontemporer kian bebas untuk mengakomodasi persentuhan, pembauran, kolaborasi antardisiplin dan medium, dalam berbagai bentuk ekspresi nilai kultural dan estetik. Keadaan ini juga berdampak pada wacana ekspresi dan teoritik dunia seni grafis. Seni grafis Indonesia tumbuh dan berkembang dalam hiruk-pikuk suasana yang demikian, bahkan sebagai penanda utama corak ekspresi seni rupa di tanah air dewasa ini. [5] Hadirnya paradigma baru dalam seni rupa ini memberikan persentuhan baru dalam praktik maupun wacana teori dalam dunia seni rupa Indonesia, demikian juga dalam seni grafis. Fenomena yang terjadi diikuti oleh munculnya karya-karya seni grafis baru yang merespon kekayaan medium dan teknologi baru disertai konsep pemikiran yang lebih plural, dan menawarkan wacana alternatifalternatif baru yang lebih dinamis.

Sebuah kontradiksi ketika prinsip seni grafis yang sangat mengutamakan kekuatan teknis, kemudian secara berangsur berubah dalam bingkai yang semakin melebar dalam pemahaman seni kontemporer yang dinafasi oleh pemikiran posmodernisme. Hal itulah wujud dari perubahan yang hendak 
disajikan dan dianalisis melalui tulisan ini, bahwa perkembangan seni grafis yang terjadi di kota Yogyakarta menjadi bahan analisis sekaligus menunjukkan terjadinya metamorfosis seni grafis konvensional menuju pada seni grafis kontemporer.

\section{$3 \quad$ Sejumlah Karya Seni Grafis Yogyakarta}

Tumbuh kembangnya seni grafis Yogyakarta, memang tidak bisa dilepaskan dari peran perguruan tinggi seni sebagai pemicu dan pencetak para pegrafis. Bagaimanapun juga, Fakultas Seni Rupa ISI Yogyakarta memiliki peran dalam melahirkan karya seni grafis Indonesia dan mencetak para pegrafis yang memberi kontribusi dalam medan sosial seni rupa Indonesia. Namun dalam perjalanan kesenian, seni grafis sampai dengan hari ini masih mengalami kendala dalam menembus persoalan apresiasi, pasar seni, dan persoalan tanya jawab ideologis yang berkepanjangan sehingga masih terus menjadi polemik yang belum juga berhenti. Lepas dari itu semua, perkembangan seni grafis Yogyakarta secara visual dan kultural menampilkan wajah yang unik untuk dicermati dan diapresiasi. Beberapa peranan dan wujud seni grafis Yogyakarta dapat dicatat dalam peta seni grafis Yogyakarta tergambar sebagai berikut :

\subsection{Seniman Angkatan 1980-an}

Pada tahun 1980-an tercatat beberapa pegrafis yang berasal dari Fakultas Seni Rupa ISI Yogyakarta memberi catatan tersendiri dalam pembaharuan dalam eksplorasi teknis dalam seni grafis. Beberapa nama penting untuk dicermati antara lain: Yamyuli Dwi Iman melalui eksplorasi teknis cetak tinggi (hardboard cut) dengan pewarnaan yang berlapis-lapis, cat yang tebal dan pemakaian cairan pengering, menjadikan karya Yamyuli penuh warna dan tebal. Secara teknis, Yamyuli menggunakan prinsip cetak dengan logika terbalik, menorehkan cat dengan warna gelap berangsur ke warna terang. Karya-karya Yamyuli memberi kontribusi tersendiri dalam pencapaian teknis seni grafis dimasa itu. Agung Kurniawan (Agung 'leak' Kurniawan) banyak menggunakan teknik cetak dalam (intaglio) dalam eksplorasi pada karya-karyanya , juga secara idiologis memberi peran dalam mempelopori kekuatan jaringan kelembagaan secara lebih luas, menciptakan ruang alternatif (mendirikan Kedai Kebun galeri dan forum, dan penyokong berdirinya Grafis Minggiran ) yang pada era tersebut belum banyak dilakukan. 


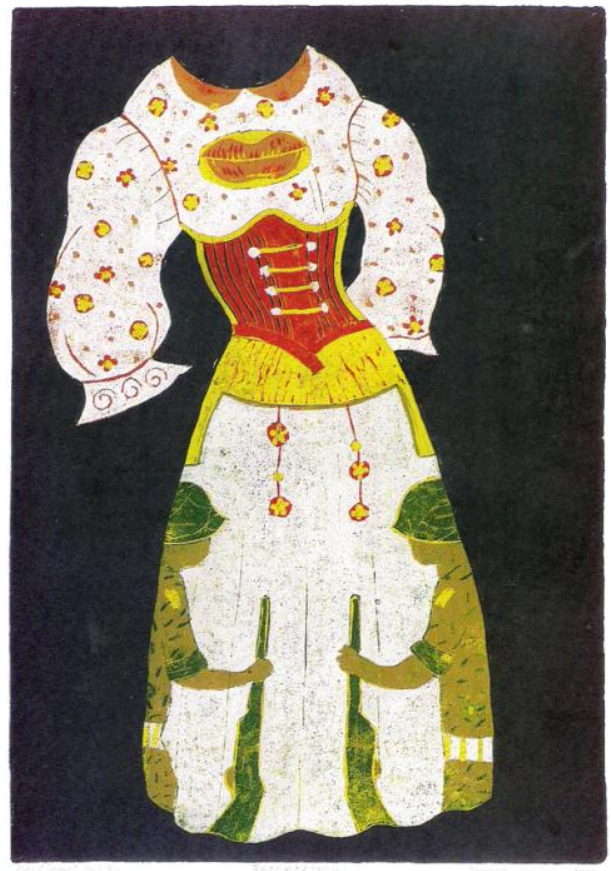

Gambar 1 Yamyuli Dwi Iman, Reforfashion 6, 1999, 32 x 46 cm, Hardboard cut, 1/3. (Sumber: Katalog Setengah Abad Seni Grafis Indonesia, 2000)

\subsection{Tema Sosial-Politik}

Pada tahun-tahun akhir masa pemerintahan Orde Baru di Indonesia (yang memanas tahun 1998), seluruh komponen bangsa ini bergerak bersama menjadi sebuah gerakan pemikiran, gerakan moral dan kultural yang kuat kemudian merespon situasi sosial-politik negri ini.

Sebagaimana diketahui, di era tahun 1950-an, kota Yogyakarta merupakan tempat yang subur bagi tumbuhnya sanggar-sanggar seni, dan tempat Lembaga Kebudayaan Rakyat (LEKRA) mengibarkan benderanya. Keikutsertaan para perupa dengan tema-tema realisme sosial dan menjadi bagian dalam organisasi lembaga tersebut telah mencatat kota Yogyakarta sebagai kota kebudayaan yang penting. Fenomena itu kemudian muncul kembali pada dekade 1990-an, para seniman mengangkat tema sosial - politik sebagai respon terhadap memanasnya iklim politik Indonesia yang ditandai dengan runtuhnya pemerintahan Orde Barudi bawah pimpinan presiden Soeharto pada bulan Mei 1998. [6] Di tahun tersebut tercatat karya-karya seni yang dihasilkan lebih banyak didominasi oleh karya-karya bertema sosial-politik, tidak terkecuali karya-karya seni grafis. 


\subsection{Taring Padi}

Para era tahun 1998, di kota Yogyakarta mencuat nama kelompok seniman 'Taring Padi' yang dikenal sebagai kelompok pekerja seni-budaya yang berproses untuk menciptakan karya-karya seni yang progresif. Awalnya kelompok ini bernama Lembaga Budaya Kerakyatan Taring Padi (LBK TP). Kegiatan yang dilakukan meliputi : penerbitan media berkala Terompet Rakyat, kerja sama antar komunitas, pembuatan media propaganda (seperti poster bertema, baliho, wayang-wayangan, instalasi), aksi grafiti, dan lain sebagainya.

Kelompok Taring Padi memakai seni grafis sebagai media penciptaan poster bertema slogan-slogan kerakyatan. Kelompok ini mencoba meniru efektifitas dan gerak perjuangan para perupa menjelang kemerdekaan yang memakai seni cetak grafis sebagai media perjuangan melawan penjajah. Pemakaian medium cetak melalui slogan-slogan kerakyatannya dikembangkan dengan keterampilan teknis yang cukup baik.

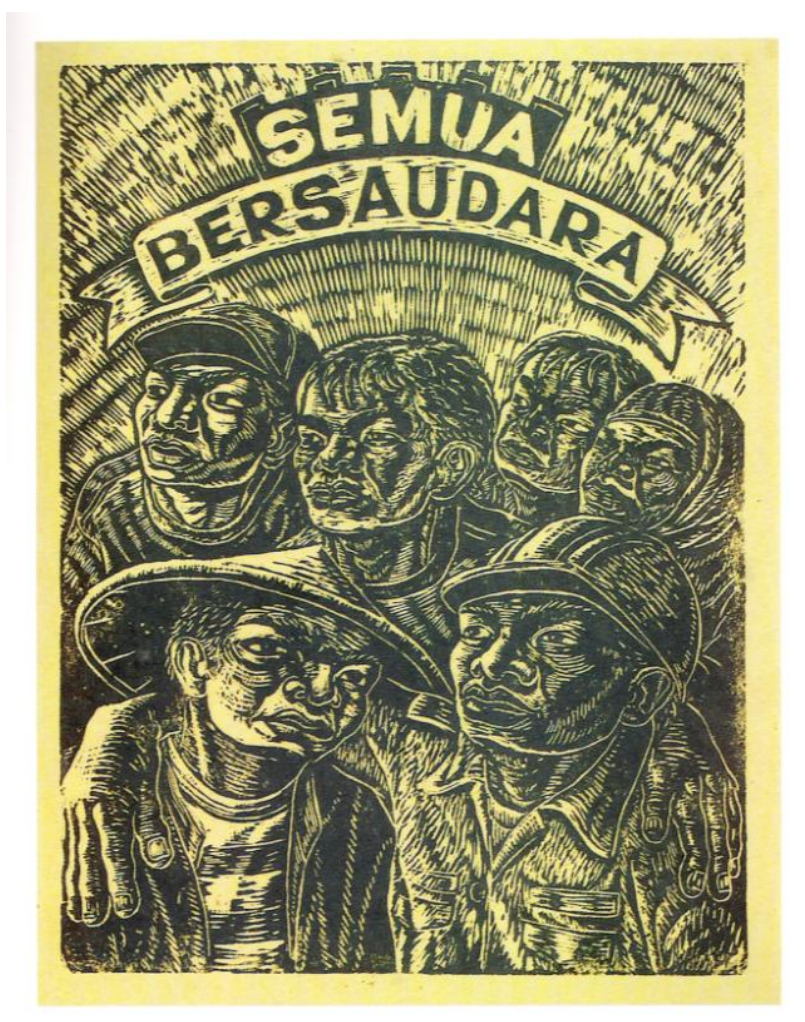

Gambar 2 Taring Padi, Semua Bersaudara (All Brothers), 45 x $60 \mathrm{~cm}$, Woodcut. (Sumber: Katalog Setengah Abad Seni Grafis Indonesia, 2000) 


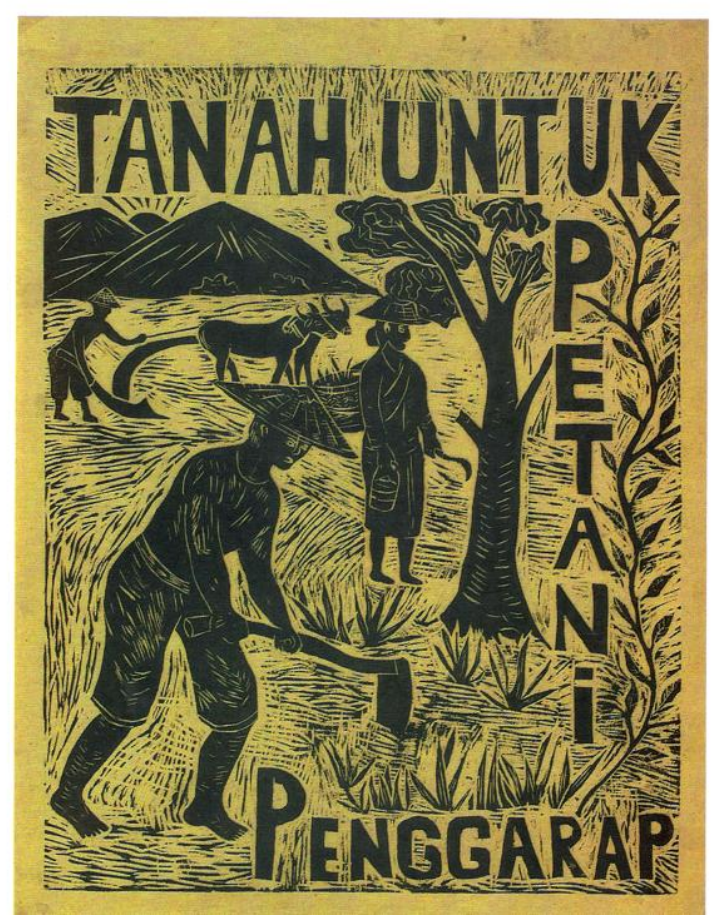

Gambar 3 Taring Padi, Tanah Milik Penggarap (The Land of Farmer), $45 \mathrm{x}$ $60 \mathrm{~cm}$, Woodcut. (Sumber: Katalog Setengah Abad Seni Grafis Indonesia, 2000)

\section{4 'Grafis Minggiran'}

Kelompok 'Grafis Minggiran' berdiri dari tanggal 1 September 2001 bertepatan dengan sebuah pameran bersama di Gelaran Budaya Yogyakarta. Berawal mengingat terbatasnya ruang pamer di kampus. Kelompok yang sebagian besar beranggotakan mahasiswa ISI Jurusan Seni Grafis ini kemudian mendirikan sebuah studio di wilayah Minggiran. Itulah sebabnya tempat yang mereka gunakan untuk berkarya dan mengembangkan seni grafis diberi nama Rumah Grafis Minggiran.

Aktivitas utama Studio Grafis Minggiran adalah menyediakan ruang dan fasilitas kerja bagi para seniman, khususnya yang bekerja dengan teknik grafis. Studio Grafis Minggiran juga bekerja untuk membangun jaringan di antara para seniman grafis di Yogyakarta, bahkan dengan studio grafis yang ada kota-kota lain. Selain sebagai ruang untuk berkarya bagi anggotanya yang kurang lebih berjumlah 30-an orang, studio Grafis Minggiran juga menerima pesanan mencetak karya grafis. Walaupun demikian, kiprah Grafis Minggiran telah 
memberi kontribusi aktif untuk pengembangan seni grafis secara lebih luas pada masyarakat.

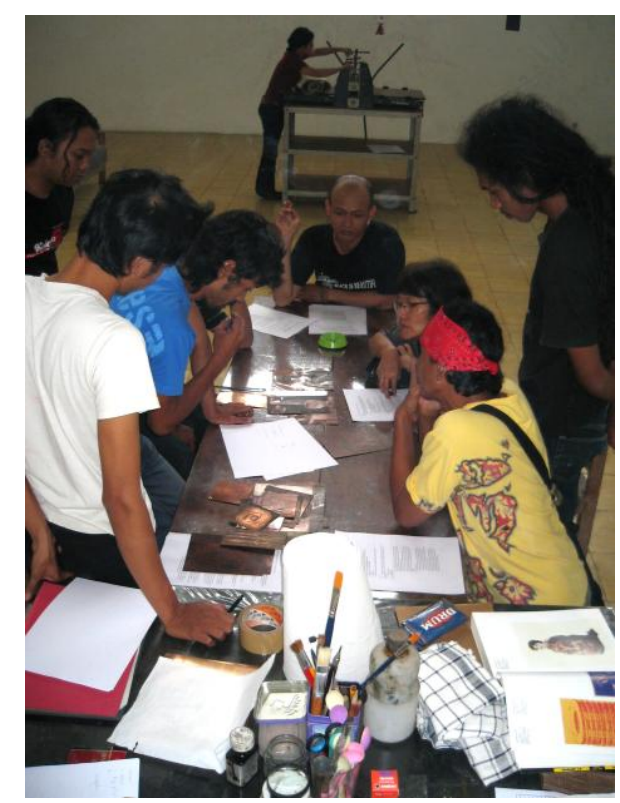

Gambar 4 Pembukaan Workshop Studio Grafis Minggiran di Rumah Seni Cemeti Yogyakarta, Desember 2006. (Sumber; foto dokumentasi Grafis Minggiran, 2006)

\subsection{Wacana Alternatif Seni Rupa Publik}

Perjalanan berikutnya di era 1990-an muncul fenomena baru dalam perkembangan seni rupa di Yogyakarta yaitu seni rupa publik dengan konsep penolakan terhadap elitisme dalam berkarya seni. Kemunculan seni rupa publik dipicu oleh pemahaman untuk memberi ruang bagi karya seni bergaya Pop Art, atau karya seni yang menampung ide-ide populer, seni yang memiliki dimensi sosial terhadap masyarakat secara lebih luas. Bentuk-bentuk manifestasinya tidak selalu dipamerkan di ruang-ruang pamer seperti galeri atau museum, tetapi lebih luas menyentuh publik atau masyarakat.

Semangat seni rupa publik Yogyakarta dimotori oleh beberapa pemunculan ruang-ruang alternatif seperti 'Apotik Komik' yang aktif menggali ide-ide wacana subkultur dan memunculkan karya-karya seni rupa publik seperti komik, mural, dan juga workshop-workshop seni rupa publik. Selain itu muncul kelompok 'Daging Tumbuh' yang juga bergerak dalam eksplorasi pembuatan komik alternatif dan menampung kelompok-kelompok atau seniman-seniman 
yang tertarik mengembangkan komik. Pada tahap selanjutnya muncul seniman personal yang aktif memberi ruang untuk pengembangan seni rupa publik seperti Arie Dyanto, Samuel Indratma. Kelompok ini adalah salah satu kelompok yang berasal dari 'Apotik Komik', namun dalam perkembangannya mencoba mengeksplorasi seni rupa publik secara lebih intensif dan meluas. Arie Dyanto mengembangkan seni cetak stensil dan air brush yang dekat dengan fenomena street art di Yogyakarta.

Arie lebih memiliki kedekatan dengan seni grafis, sehingga pada tahap selanjutnya membawa pengaruh pada kecenderungan seni grafis alternatif hasil karya mahasiswa seni grafis FSR ISI Yogyakarta. Sedangkan Samuel Indratma mencoba mendekatkan lebih jauh mengenai seni rupa publik melalui workshopworkshop dengan sasaran masyarakat umum dan anak-anak sekolah. Kelompok ini mau terjun menjadi bagian dalam pengembangan seni rupa publik kota Yogyakarta secara lebih kongkrit.

Melihat kecenderungan fenomena seni rupa alternatif di Yogyakarta, memberi angin segar bagi 'kemandegan' cara berungkap seni yang selama ini diakui secara konvensional seperti seni lukis, seni grafis dan seni patung. Keaktifan para perupa dalam cara berungkap seni yang 'baru', ini juga menimbulkan stimulan-stimulan aktif bagi sejumlah perupa di jamannya dan menjadi catatan penting dalam perkembangan seni rupa Yogyakarta.

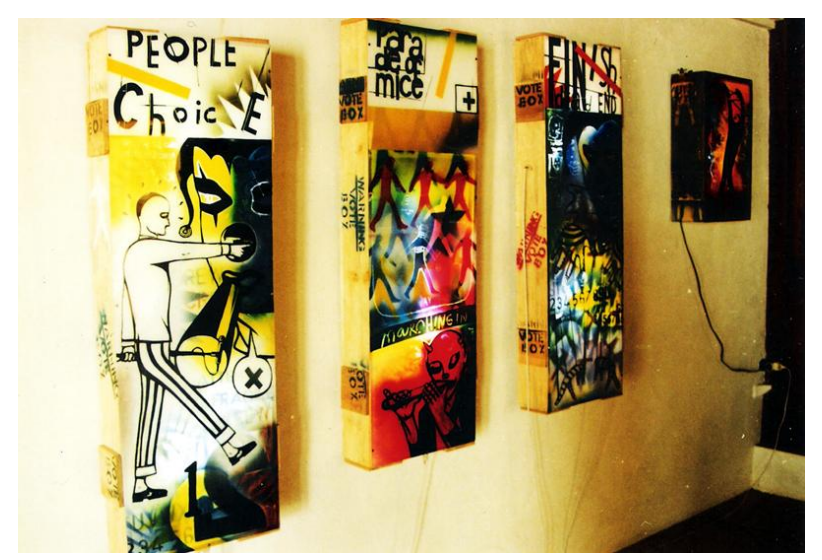

Gambar 5 Arie Dyanto, Political Asylum, Neon box, mixed media, 1998. (Sumber: foto dokumentasi penulis pada pameran di Galeri Cemeti Yogyakarta, 1998) 


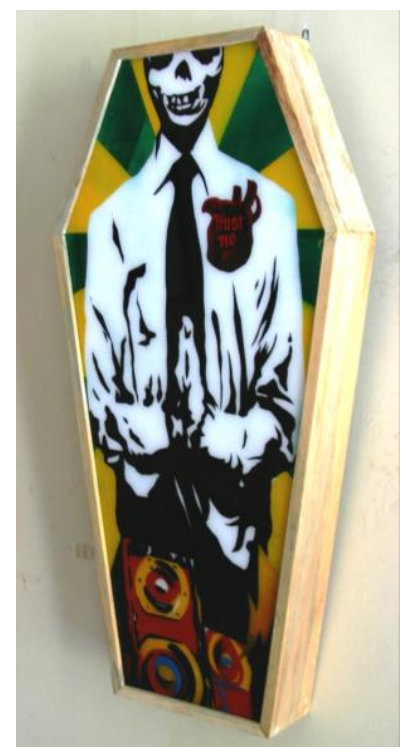

Gambar 6 Prayogo Satrio Utomo, The Dead Boy, stencil spray on acrylicneon box, 2005. (Sumber: foto dokumentasi penulis pada Pameran Grafis VI FSR ISI Yogyakarta, 2005)

\section{$4 \quad$ Simpulan}

Mengamati sejumlah tampilan karya-karya seni grafis Yogyakarta dan berbagai kecenderungan media baru yang digunakannya, dapat dikatakan bahwa seni grafis Yogyakarta menampilkan wajah seni grafis yang semakin mencerahkan. Dalam arti bahwa, dinamika kesenian yang bergerak di kota Yogyakarta memberi dampak positif bagi perkembangan seni grafis Yogyakarta. Tercatat berbagai tampilan seni grafis baik secara visual dan konseptual, kiranya dapat ditarik simpul-simpul berikut ini.

Pertama, secara visual bahwa seni grafis Yogyakarta tidak dapat jika dikatakan mengalami stagnasi atau berhenti. Aspek teknis dalam seni grafis memang sangat mendominasi cara kerja seni grafis, namun tidak berarti bahwa ketentuan teknis tersebut mengikat kendali kreativitas yang menjadi hak setiap pegrafis untuk melakukan terobosan teknis dengan muatan nilai-nilai pembaharuan, menawarkan tampilan estetik baru. Seni grafis Yogyakarta mengalami perluasan cara kerja visual, dari yang sifatnya konvensional menuju pada polapola kerja non-kovensional. Secara lebih khusus, seni grafis Yogyakarta memperlihatkan intensitas perubahan wujud dan konseptual, baik secara teknis maupun gagasan. Terdapat kecenderungan untuk 'meruntuhkan batas-batas' antara seni yang elitis (seni tinggi) dan seni rupa publik, batas antara pemahaman teknis konvensional dengan yang non-konvensional. 
Kedua, secara konseptual hendaklah dapat dibaca bahwa seni grafis Yogyakarta mengalami dialektika yang subur dan berkembang dengan medan sosial seni di sekitarnya. Terjadi aksi-reaksi antara pegrafis dan pemikiran-pemikiran yang berkembang di jamannya yang memberi stimulus positif untuk memekarkan ide dan gagasan para pegrafis. Keterbacaan terhadap pemikiran-pemikiran seni yang berkembang, keterlibatan pegrafis dalam penyelenggaraan kompetisi seni grafis (Triennale Seni Grafis yang diprakarsai Bentara Budaya Jakarta dan Kompas), keikut sertaan para pegrafis dalam pameran tingkat nasional dan internasional, akan terus mengasah kepekaan konseptual secara lebih luas.

Ketiga, bahwa upaya-upaya ruang alternatif (gerakan nyata seperti yang dilakukan 'Grafis Minggiran', Arie Dyanto yang membuka katup seni tinggi dan seni populer) merupakan upaya terobosan untuk mengenalkan, menggali potensi teknik grafis alternatif, mensosialisasikan seni grafis secara lebih kongkrit kepada masyarakat. Dengan demikian proses apresiasi yang terjadi di masyarakat semakin menguat, selain juga upaya memperbanyak pameranpameran seni grafis secara lebih intensif.

Akhirnya bahwa upaya untuk memperluas jaringan, memperbanyak hubunganhubungan antara infra struktur lembaga pendidikan seni grafis dengan dunia di sekelilingnya secara lebih luas menjadi potensi yang perlu dicatat dalam perkembangan seni grafis dalam wacana seni kontemporer Yogyakarta. Terjadinya interrelasi antara seni grafis konvensional dan wacana seni alternatif modern serta perkembangan teknologi menjadi ruang dialog terus-menerus demi melahirkan karya-karya seni grafis yang selalu dapat merespon jamannya. Oleh karena itu, peran kalangan pegrafis maupun infrastruktur kesenian menjadi penting sebagai penentu perkembangan seni grafis Yogyakarta ke depan. Kiranya bahwa sikap menjelajah atau sikap eksperimental, dan sikap kritis seperti yang dikatakan Sanento Yuliman selalu menjadi jiwa dalam perkembangan seni grafis ke depan.

\section{Referensi}

[1] Supriyanto, Enin, Mulyadi, Efix, dkk., 2000, Pengantar Setengah Abad Seni Grafis Indonesia, Kepustakaan Populer Gramedia dan Bentara Budaya Jakarta-Yogyakarta, halaman 4.

[2] Siregar T.H., Aminudin, 2005, Kedudukan Seni Grafis dalam Seni Rupa Kita, Makalah Seminar Seni Grafis 2005, Galeri Soemardja FSRD ITB, halaman 5.

[3] Yuliman,Sanento, 2001, Dua Seni Rupa, Sepilihan Tulisan Sanento Yuliman, Penerbit Yayasan Kalam, Jakarta, halaman 59. 
[4] Wisetromo, Suwarno, 1998, Melacak Garis Waktu dan Peristiwa, Direktorat Jenderal Kebudayaan Departemen Pendidikan dan Kebudayaan, Jakarta, halaman 24.

[5] Sabana, Setiawan. Jejak Teknologi, Catatan Zaman, (download dari www.kompas.com, Minggu, 1 Oktober 2006, jam 14.12)

[6] Sri Wulandari, Wiwik, 2000, Tema Sosial Politik dalam Seni Rupa Kontemporer Yogyakarta dekade 1990-an, Skripsi Jurusan Seni Murni Fakultas Seni Rupa ISI Yogyakarta. 